\title{
Elevationen der Autorschaft
}

\section{Hartmut Bleumer}

Online publiziert: 6. Februar 2018

(C) Springer-Verlag GmbH Deutschland, ein Teil von Springer Nature 2018

Die literaturwissenschaftliche Frage nach dem Autor lässt sich offenbar nicht stillstellen. Ihre Dynamik ist so alt, aber auch so lebendig wie die Literatur selbst. Nicht zuletzt aus dieser historischen Dynamik resultieren die eigentümlichen Schwierigkeiten des Umgangs mit der Autorkategorie: Im historischen Wandel von kulturellen und medialen Situationen entsteht der Anschein, man könne den Autor verabschieden oder zurückholen - und doch behauptet sich in diesem Anschein zugleich auch dessen unverminderte Notwendigkeit. Die breiten literaturwissenschaftlichen Diskussionen zum Thema gerade der letzten Jahre haben darum zwar etwas unvermindert Florierendes, indes ebenso etwas Kreisendes. Jedenfalls scheint es angesichts der Fülle von Äußerungen zunehmend schwierig zu sein, die Systematik der Debatten zu durchschauen und dann den je eigenen wissenschaftlichen Standort anzugeben.

Das Konzept des folgenden Heftes schlägt dazu eine Selbstbestimmung über den Ansatz des >religiösen Wissens< vor. Denn auch dieses >religiöse Wissen< ist schon von vornherein ein durchaus schwieriges Modell. Und gerade seine Schwierigkeit erinnert wohl kaum zufällig an die Probleme im Umgang mit der Autorkategorie. Es könnte nämlich jene prekäre Spannung zwischen Glauben und Wissen sein, die dem religiösen Wissen von Anfang an eingeschrieben, aber auch durch die Schrift in die Latenz abgedrängt ist, die auch in der Diskussion um den Autorbegriff immer wieder zurückkehrt und jenseits der Religion in der diesseitigen Literatur geradezu eine poetische Elevation des Autors erlaubt.

Das entsprechende Konzept, dem die Beiträge dieses Heftes zuarbeiten, stammt von Gudrun Bamberger, Jan Stellmann und Moritz Strohschneider, die gemeinsam am Tübinger DFG-Graduiertenkolleg $1662 »$ Religiöses Wissen im vormodernen Eu-

H. Bleumer $(\bowtie)$

Seminar für Deutsche Philologie, Universität Göttingen, Göttingen, Deutschland

E-Mail: hbleume@gwdg.de 
ropa (800-1800)« im März 2015 einen Workshop zum Thema veranstaltet haben. Aus dieser Veranstaltung sind die folgenden Aufsätze hervorgegangen. Die weitere Vorbereitung der Texte für den Druck wurde dann federführend von Gudrun Bamberger vorgenommen, bevor die Endredaktion durch den mediävistischen Herausgeber der Zeitschrift für Literaturwissenschaft und Linguistik erfolgt ist. Auf diese Arbeitsteilung ist hier ausdrücklich hinzuweisen: Dass der Name von Frau Bamberger zuerst genannt werden muss, ist also beileibe nicht nur eine Frage des Alphabets, sondern auch und vor allem ihrer konzeptionellen Verantwortung für dieses Heft geschuldet, und darin steht sie wiederum nicht allein. 